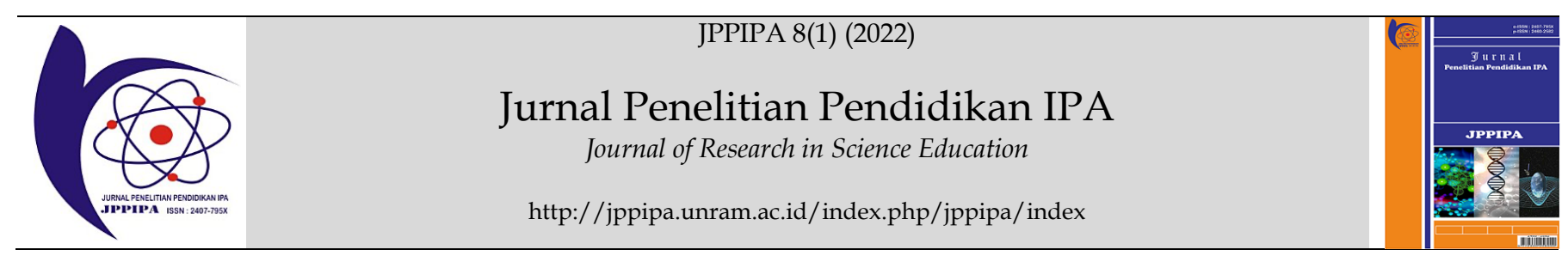

\title{
Characterization of PVA-Enzyme Coated Indicator Electrodes GA coated again with PVC-KTpCIPB-o-NPOE SEM-EDS, FTIR and XRD analysis.
}

\author{
Abd Hakim S1* \\ ${ }^{1}$ Department of Physics, Faculty of Mathematics and Natural Sciences, Universitas Negeri Medan, Indonesia
}

DOI: $\underline{10.29303 / \text { jppipa.v8i1.1265 }}$

\section{Article Info}

Received: November 30, 2021

Revised: December 27, 2021

Accepted: January 8, 2022

Published: January 31, 2022

\begin{abstract}
This study aims to characterize the tungsten-urea analyte indicator electrode. The method used is biosensor potentiometry with urease enzyme immobilization technique. This indicator electrode was coated with PVA-enzyme coated with glutaraldehyde (GA) $2.9 \%$ coated with PVC-KTpCIPB- o-NPOE with o-NPOE variation of $61 \%$ and $66 \%$. Characterization of coated indicator electrodes using SEM-EDS, FTIR and XRD analysis. A1-4 61\% indicator electrode sample coated PVA-enzyme 1x coated with glutaraldehyde (GA) 2.9\% 1x coated PVC-KTpClPB- o-NPOE 1x, with o-NPOE 61\%. A3-4 61\% indicator electrode sample coated PVA-enzyme 3x coated with glutaraldehyde (GA) 2.9\% 1x coated PVC-KTpCIPB- o-NPOE 1x, with o-NPOE 61\%. Likewise, the reasoning of samples A1-4 $66 \%$ and A3-4 66\%. There are four indicator electrodes made with the notation A1-4 $61 \%$, A1-4 66\%, A3-4 61\% and A3-4 66\%. The best results were obtained at the indicator electrode sample A1-4 61\%, contributing to the urea sensor of the potentiometer cell
\end{abstract}

Keywords: Tungsten indicator electrodes; GA and o-NPOE; SEM-EDS; FTIR and XRD; Biosensor Potentiometry; Immobilization.

Citation: Hakim, S.A. (2022). Characterization of PVA-Enzyme Coated Indicator Electrodes GA coated again with PVCKTpCIPB-o-NPOE SEM-EDS, FTIR and XRD analysis. Jurnal Penelitian Pendidikan IPA, 8(1), $103-108$. https:// doi.org/10.29303/jppipa.v8i1.1265

\section{Introduction}

Research has been carried out on indicator electrodes coated with PVA-enzyme coated with PVC$\mathrm{KTpClPB}$ with a detection range of $10^{-5}-10^{-4} \mathrm{M}$ (Hakim, 2019). This electrode analysis has been characterized using SEM-EDS (Hakim, 2018). According to (Rahman, 2008) the range is $5 \cdot 10^{-7}-10^{-2} \mathrm{M}$. On this basis the researchers increased the detection range with GA and o-NPOE. Experimental research on indicator electrodes B1-4 and B3-4 has been carried out. B1-4 is an indicator electrode coated with PVA-Enzyme 1x coated GA $1 x$ coated again with PVC-KTpCIPB 1x. B3-4 is an indicator electrode coated with PVA-Enzyme $3 x$ coated GA $1 x$ coated again with PVC-KTpCIPB. B1-4 and B3-4 analyzed by SEM-EDS can be seen in Table 1.

Research experiments have been carried out with indicator electrodes A1-4 61\%, A1-4 66\%, A3-4 61\% and A3-4\%. The results can be seen in Table 2. Indicator electrodes A1-4 61\% were indicator electrodes coated with PVA-Enzyme $1 x$ coated with GA $1 x$ coated again with PVC-KTpCIPB-o-NPOE $1 x$ with o-NPOE $61 \%$. Indicator electrodes A1-4 66\% are indicator electrodes coated with PVA-Enzyme 1x coated with GA 1x coated again with PVC-KTpCIPB-o-NPOE 1x with o-NPOE $66 \%$. Indicator electrode A3-4 $61 \%$ is indicator electrode coated with PVA-Enzyme 3x coated GA 1x coated again with PVC-KTpCIPB-o-NPOE 1x with o-NPOE $61 \%$. Indicator electrode A3-4 66\% is indicator electrode coated with PVA-Enzyme 3x coated GA 1x coated again with PVC-KTpCIPB-o-NPOE $1 x$ with o-NPOE $66 \%$.

To coat the PVA indicator electrode, enzyme, PVC$\mathrm{KTpClPB}$, o-NPOE in solution form. PVA $0.0350 \mathrm{~g}$ dissolved in $10 \mathrm{~mL}$ of hot water to cool in a glass tube. PVC $0.0350 \mathrm{~g}+\mathrm{KTpClPB} 0.0500 \mathrm{~g}$ dissolved in $10 \mathrm{~mL}$ THF in a glass tube and covered with a plastic cover/aluminum foil. 2.9\% GA solution is $0.29 \mathrm{~g}$ of GA

\footnotetext{
*Email: abdhakims@unimed.ac.id
} 
in $10 \mathrm{~mL}$ of distilled water. The o-NPOE solution consisted of $5 \mathrm{~mL}, 61 \%(0.0647 \mathrm{gr}=0.0622 \mathrm{~mL})$ and $66 \%$ $(0.0700 \mathrm{gr}=0.0673 \mathrm{~mL})$.

Based on Table 1. the weight percent of tungsten sample B1-4 is $73.68 \%$, B3-4 is $76.24 \%$. Likewise, Table 2 weight percent of tungsten samples A1-4 $61 \%$ is $91.91 \%, \mathrm{~A} 3-461 \%$ is $95.98 \%, \mathrm{~A} 1-466 \%$ is $84.93 \%$ and A3- $466 \%$ is $79.81 \%$. There was an increase in weight percent of tungsten with the addition of o-NPOE $61 \%$ and $66 \%$ through EDS analysis. The morphology of the indicator electrodes A1-4 61\%, A3-4 61\%, A1-4 66\% and A3-4 66\% can be seen in Figure 1. The best four samples have not been selected, for this reason, FTIR and XRD analysis are carried out.

An ion selective electrode (ISE) has been used (Huang, et al., 2014) with 2-nitrophenyloctyl ether (NPOE) and mixed in poly(vinyl chloride) (PVC). The obtained sensitivity is $19.7 \mathrm{mV} /$ decade with a range of 5.10-7-10-2 M. According to (Rahman, 2008) the optimum sensitivity is $59 \mathrm{mV} /$ decade, for a reaction to be reversible (in practice the difference is typically between $70-100 \mathrm{mV}$ ).

The immobilization technique in the construction of the biosensor involves the urease enzyme and a polymer consisting of PVC for the urea bioser (Ulianas, et al., 2011). Poly(vinylchloride) (PVC) is a polymer matrix commonly used in ISE (Mir, et al., 2014).

The permissible limit of PVC on the membrane electrode has the composition of PVC: o-NPOE: DPA: NaTPB as 33:61:3:3 (w/w) as the optimum composition with the closest Nernstian response (Kaur, et al., 2017). The composition according to (Badakhshan, et al., 2019) is 30:65.5:0.5 mg of PVC: o-NPOE: KTpClPB, as a composition of PVC, plasticizer and lipophilic additive. Ionophores (I) 1.10\% (w/w), lipophilic salt (KTpClPB) $0.25 \%(\mathrm{w} / \mathrm{w})$, plasticizer (o-NPOE) $65.65 \%(\mathrm{w} / \mathrm{w})$, and PVC $33.00 \%(\mathrm{w} / \mathrm{w})$ dissolved in tetrahydrofuran (Lenar, 2020; Hasan, 2019); 0.05 wt $\%$ KTpCIPB as membrane additive, and $1 \mathrm{wt} \%$ ionophore, $33 \mathrm{wt} \% \mathrm{PVC}$ and $66 \mathrm{wt} \%$ plasticizer (o-NPOE) (Rizk, et al, 2009); 62.5 mg PVC, $130 \mathrm{mg}$ o-NPOE, 1\% by weight $\mathrm{s}$ prepared containing $62.5 \mathrm{mg}$ PVC, $130 \mathrm{mg}$ o-NPOE, 1\% by weight ionophore and 80 to $140 \mathrm{~mol} \%$ KTpClPB (relative to the ionophore). The membrane components were dissolved in $1.5 \mathrm{~mL}$ of THF (Pomećko, et al., 2021).

\section{Method}

The materials used in the manufacture of the indicator electrodes were tungsten with a diameter of $1.0 \mathrm{~mm}$ 99.99\% Aldrich 267562, PVA [- $\left.\mathrm{CH}_{2} \mathrm{CHOH}-\right] \mathrm{n}$, enzyme EC 3.5.1.5 (Urease) U4002, 50 - 100 ku type ix, glutaraldehyde (GA); PVC $\left(\mathrm{CH}_{2} \mathrm{CHCl}\right) \mathrm{n}$, potassium tetrakis (4-chlorophenyl) borate (KTpClPB), o- nitrophenyloctylether (o-NPOE), Tetrahydrofuran $\mathrm{C}_{4} \mathrm{H}_{8} \mathrm{O}$, all from Sigma-Aldrich.

The indicator electrodes were made by using the potentiometric biosensor of the urease enzyme immobilization technique in two notations B1-4 2.9\% GA and B3-4 2.9\% GA. Then analyzed by SEM-EDS. From the two samples above, it was continued to manufacture four indicator electrodes with notation A1-4 61\%, A3-4 61\% and A1-4 66\%, A3-4 66\%. Then the four were analyzed by SEM-EDS, FTIR and XRD.

\section{Result and Discussion}

\section{Hasil analisis EDS dan SEM}

Analysis of indicator electrodes B1-4 and B3-4 using EDS and SEM has not been able to ensure the best indicator electrode samples. For strong conclusions, further FTIR and XRD analyzes are needed.

Table 1. Weight percent, atomic and atomic ratio of Tungsten without o-NPOE.

\begin{tabular}{lllll}
\hline $\begin{array}{l}\text { Indicator } \\
\text { electrode (\%) }\end{array}$ & Element & Weight \% & Atomic\% & $\begin{array}{l}\text { Ratio } \\
\text { Atomic }\end{array}$ \\
\hline B1-4 & $\mathrm{W}$ & 73.68 & 80.30 & 2.41 \\
B3-4 & $\mathrm{W}$ & 76.24 & 87.78 & 2.49 \\
\hline
\end{tabular}

After UV-Vis and SEM-EDS analysis, samples of indicator electrodes B1-4 and B3-4 without o-NPOE were further analyzed by cell potentiometer, to characterize their sensitivity and detection range. The best results were obtained at the indicator electrode B14.

Table 2. Weight percent, atomic and atomic ratio of Tungsten Using o-NPOE.

\begin{tabular}{lllll}
\hline $\begin{array}{l}\text { Indicator } \\
\text { electrode }(\%)\end{array}$ & Element & $\begin{array}{l}\text { Weight } \\
\%\end{array}$ & $\begin{array}{l}\text { Atomic } \\
\%\end{array}$ & $\begin{array}{l}\text { Ratio } \\
\text { Atomic }\end{array}$ \\
\hline A1-4 61 & w & 91.91 & 91.80 & 2.93 \\
A3-4 61 & W & 95.98 & 92.78 & 3.04 \\
A1-4 66 & W & 84.93 & 86.27 & 2.74 \\
A3-4 66 & w & 79.81 & 87.45 & 2.59 \\
\hline
\end{tabular}

However, samples B1-4 and B3-4 continued to the next step in the manufacture of indicator electrodes A1$461 \%$, A3-4 61\%, A1-4 66\% and A3-4 66\%, the results of the SEM analysis can be seen in Figure 1 and EDS Table 1.

SEM-EDS analysis for indicator electrodes having o-NPOE can be seen in table 2. The weight percent of tungsten A1-4 $61 \%$ is $91.91 \%$ and the weight percent of tungsten A3-4 $61 \%$ is $95.98 \%$. The weight percent of tungsten A1-4 66\% was $84.93 \%$ and the weight percent of tungsten A3-4 $66 \%$ was $79.81 \%$. The largest weight percentage of tungsten was at the best $61 \%$ o-NPOE content at the indicator electrodes A1-4 61\% and A3-4 $61 \%$. A good SEM morphological analysis of the 
membrane was also found at the indicator electrodes A1-4 $61 \%$ and A3-4 61\%, the pores slightly increased the weight percent of tungsten. At the indicator electrodes A1-4 66\% and A3-4 66\% the number of pores reduces the weight percent of tungsten.

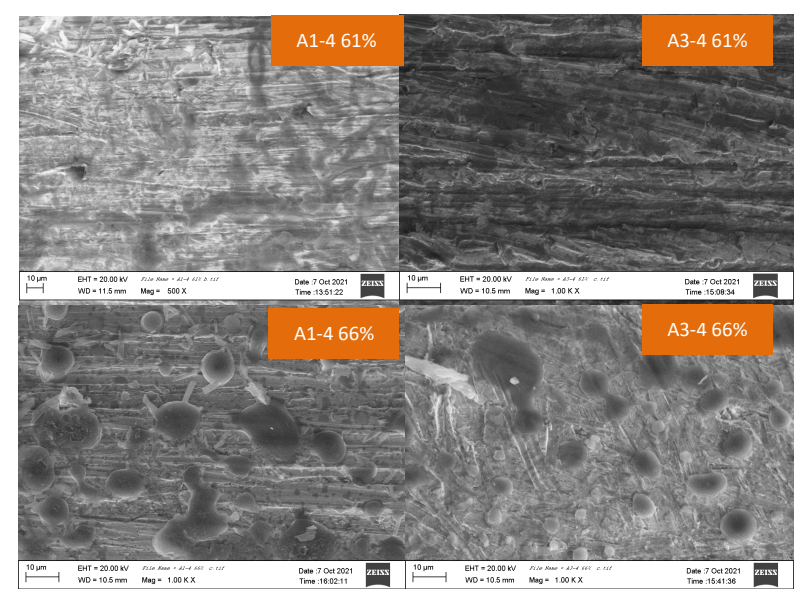

Figure 1. Morphology of sample size $10 \mathrm{~m}$ voltage $20 \mathrm{kV}$ magnification $600 \times(\mathrm{A} 1-461 \%)$ and $100 \times(\mathrm{A} 3-4$ 61\%, A1-4 $66 \%$ and $\mathrm{A} 3-466 \%)$.

Morphology of indicator electrodes A1-4 61\% EDS analysis peak intensity $4.3 \mathrm{keV}$ weight percent tungsten 91.91\%; morphology of indicator electrodes A1-4 66\% EDS analysis peak intensity $2.5 \mathrm{keV}$ weight percent tungsten $84.93 \%$; morphology of indicator electrode A3-4 61\% EDS analysis peak intensity $4.3 \mathrm{keV}$ weight percent tungsten $95.98 \%$; morphology indicator electrode A3-4 66\% EDS analysis peak intensity $4.5 \mathrm{keV}$ weight percent tungsten $79.81 \%$. This confirmed the high purity of the prepared tungsten (Shawky, 2021).

\section{FTIR Characterization Results using o-NPOE}

The characterization of indicator electrodes A1-4 $61 \%, \mathrm{~A} 3-461 \%, \mathrm{~A} 1-466 \%$ and $\mathrm{A} 3-466 \%$ can be seen in Figure 2. The FTIR spectrum pattern for A1-4 61\% indicator electrodes has a transmittance percentage between $85-100$. The spectrum pattern of A1-4 is $61 \%$ similar to (Badakhshan, et al., 2019), the transmittance percent is between 90-100. There is an increase in \% Transmittance of the FTIR spectrum pattern by an increase in o-NPOE. Meanwhile, A1-4 66\% and A3-4 $66 \%$ decreased the transmittance of the FTIR spectrum pattern by increasing o-NPOE.

According to Elbehery, (2019), plasticizer (either DOP or o-NPOE, $133 \mathrm{mg})$, and PVC (66 mg) in THF (3 $\mathrm{mL}$ ), (Hassan, 2019) The composition of the membrane was $32.0 \mathrm{wt}$ \% PVC, $65.0 \mathrm{wt}$. \% plasticizer, and $3.0 \mathrm{wt} . \%$ ionophore. (Badakhshan, et al., 2019) $30.0 \mathrm{mg}$ of PVC, $65.5 \mathrm{mg}$ of $\mathrm{o}-\mathrm{NPOE}$, and $0.5 \mathrm{mg}$ of KTpClPB were dissolved in $3 \mathrm{ml}$ of THF to make a polymer membrane. (Kaur, Chhibber and Mittal, 2017) The variation of plasticizers, lipophilic salts, and PVC within the permissible limits makes the membrane electrodes have a PVC composition: o-NPOE: DPA: NaTPB as 33:61:3:3 $(\mathrm{w} / \mathrm{w})$. (Amr, 2021) $2 \mathrm{mg}$ potassium tetrakis (4chlorophenyl) borate, $63.0 \mathrm{mg}$ o-NPOE, and $34.0 \mathrm{mg}$ PVC; all in $2 \mathrm{~mL}$ THF. (Alarfaj, N.A. and El-Tohamy, M. F., 2020) PVC $190 \mathrm{mg}$, plasticizer (o-NPOE, $0.35 \mathrm{~mL}$ ) in $5 \mathrm{~mL}$ THF.

$66.5 \mathrm{mg}$ PVC, $127 \mathrm{mg}$ plasticizer (o-NPOE) and 2.2 $\mathrm{mg}$ potassium tetrakis (3.5-bis (trifluoromethyl) phenyl) borate (KTFPB) were thoroughly mixed in a $3 \mathrm{~cm}$ diameter petri dish and dissolved in $3 \mathrm{~mL}$ (Kamel, et al, 2020).

Although the dielectric constant $=24$ of o-NPOE is the highest value, it does not significantly affect the membrane potentiometric detection limit in the case of drugs (Hassan, 2020).

The observed absorption bands at $745 \mathrm{~cm}^{-1}$ and $1081 \mathrm{~cm}^{-1}$ associated with the $\mathrm{C}-\mathrm{Cl}$ and $\mathrm{B}-\mathrm{C}$ stretches, respectively confirmed the presence of the lipophilic additive KTpClPB. The presence of PVC as an inert membrane matrix was confirmed by the gauche absorption band observed in the $669 \mathrm{~cm}^{-1}$ region (Badakhshan, 2019).

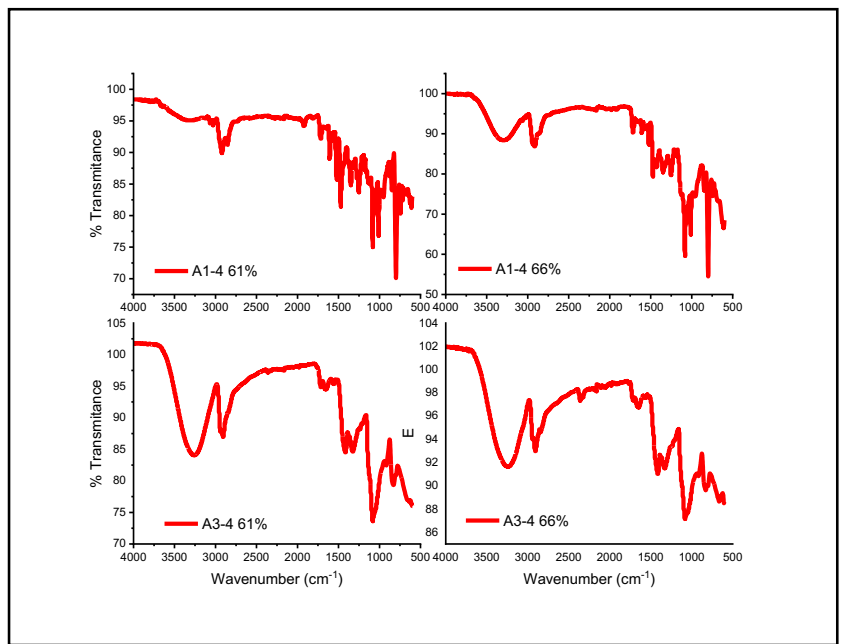

Figure 2. Spectrum pattern \% Transmittance A1-4 61\%, A1-4 66\%, A3-4 61\% and A3-4 66\%.

The ratio of plasticizer/PVC plays a major role to obtain optimal response. o-NPOE was chosen as a plasticizer because of the good solubility of the membrane components and high dielectric constant. Meanwhile, NaTPB is used as a lipophilic additive because of its important role in increasing the sensitivity and selectivity of the electrode and reducing anionic interference (Alharthi, et al., 2021). The lipophilic additive in this study was $\mathrm{KTpCIPB.}$

UV-Vis spectroscopy is the most useful and reliable technique for confirming the main characterization of the size, shape and stability of the nanostructures of metal oxides synthesized in liquid suspension. According to the analysis (Shawky, 2021; Al-Mohaimeed, et al, 2021) the increase in the 
absorption peak with respect to the wavelength has an effect on the increase in \% Transmittance of the wave number.

According to Alharthi, et al., (2021), the increase in $\%$ Transmittance with respect to the wavelength of the FTIR, was followed by an increase in the peak intensity with respect to the atomic elements of the EDS. If you observe Figure 2 of the FTIR spectrum pattern, compared to Table 2 of the high peak intensity of EDS, there is only one best sample, namely A1-4 61\%. It can be seen in Table 3 . the following is the relationship between the composition of o-NPOE in PVC with weight percent and peak intensity height and the pattern of the FTIR spectrum.

Table 3. The relationship between tungsten weight percent, EDS intensity peak height and FTIR. spectrum pattern

\begin{tabular}{llll}
$\begin{array}{l}\text { Sample } \\
(\%)\end{array}$ & $\begin{array}{l}\text { Weight } \\
\text { percent } \\
\text { Wolfram (\%) }\end{array}$ & $\begin{array}{l}\text { High Peak } \\
\text { intensity } \\
\text { (EDS) keV }\end{array}$ & $\begin{array}{l}\text { FTIR Spectrum } \\
\text { Pattern }\end{array}$ \\
\hline A1-4 61 & 91.91 & 4.30 & Increase \\
A1-4 66 & 84.93 & 2.50 & Decrease \\
A3-4 61 & 95.98 & 4.30 & Decrease \\
A3-4 66 & 79.81 & 4.50 & Decrease \\
\hline
\end{tabular}

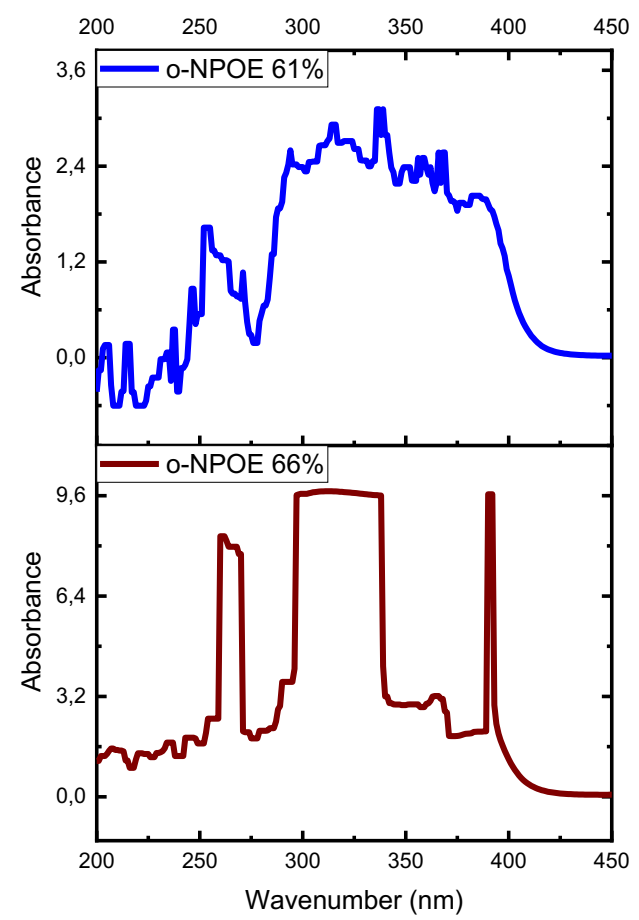

Figure 3. Absorbance spectrum pattern of PVC-KTpClPB-oNPOE at o-NPOE 6 and $66 \%$.

Research experiments have been carried out with UV-Vis analysis, the absorbance spectrum pattern of PVC-KTpCIPB-o-NPOE at o-NPOE 61\% two absorption peaks at $250 \mathrm{~nm}$ and $337 \mathrm{~nm}$; at o-NPOE 66\% three absorption peaks of 262, 320 and $390 \mathrm{~nm}$. Meanwhile, the best PVA-Enzyme-GA absorbance spectrum pattern was at GA $2.9 \%$, with a peak absorbance height of 300 $\mathrm{nm}$. There is an increase in the absorbance peak with the addition of the concentration of o-NPOE (Hassan, et al., 2020), and an increase in the absorbance of ionopores with the addition of metal salts (Golcs, et al., 2018).

\section{XRD Characterization Results using o-NPOE}

XRD is an analytical method for estimating and measuring different crystal forms in the tested samples (Shawky, 2021). Alarfaj, and El-Tohamy, (2020) have used the characterization of UV-Vis, FT-IR, XRD, and EDX spectroscopic methods in determining the calibration curve of the potentiometric system of the oNPOE modified coated wire membrane sensor. There was a change in the XRD spectrum pattern (Hakim et $\mathrm{al}, 2021)$ of KTpClPB as shown in Figure 4.

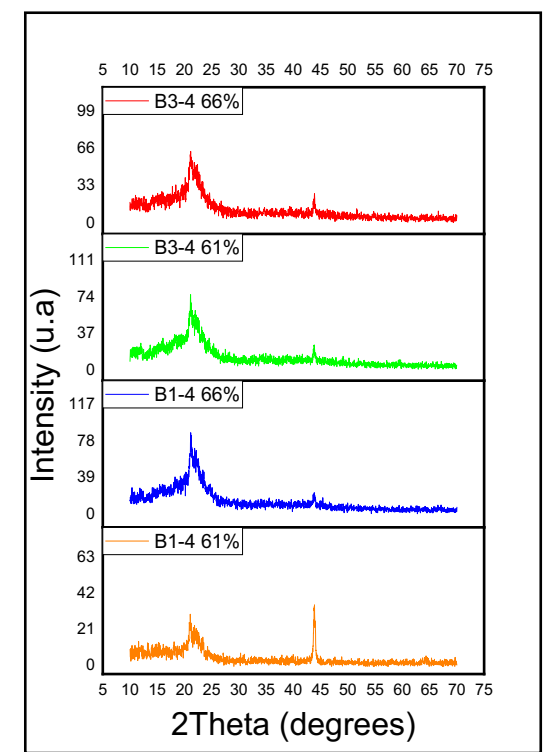

Figure 4. XRD diffraction spectrum patterns A1-4 61\%, A1-4 $66 \%, \mathrm{~A} 3-461 \%$ and A3-4 66\%.

According to El-Naby, (2019), CE NaTPB ionophore based polymer membrane sensor with incorporation of anionic additives; potassium tetrakis(p-chlorophenyl)borate $(\mathrm{KTpClPB})$ produces an excellent "CE NaTPB/KTpClPB" sensor. High sensitivity with a response slope closer to the ideal Nernstian value and a wider linear range and anionic additives cause a dramatic increase with the o-NPOE plasticiser in the lower limit of detection $5.10^{-5} \mathrm{M}$ (with a DOP limit of detection of 7.5.10-7 M), also improves the interfacial ion exchange kinetics.

According to Kaur, et al., (2017), response time is an important parameter to evaluate the working efficiency of the electrode, the best content of o-NPOE in PVC is $61 \%$. 


\section{Conclusion}

Based on the data above, the manufacture of tungsten indicator electrodes with the best membrane modifications at B1-4 and A1-4 61\%. B1-4 membrane consists of $1 x$ PVA-E coated GA $1 x$ coated PVC-KTpCIPB 1x. A1-4 61\% membrane consists of 1x PVA-E coated GA 1x PVC-KtpCIPBo-NPOE coated $1 x$.

\section{References}

Alarfaj, N. A., \& El-Tohamy, M. F. (2020). New Functionalized Polymeric Sensor Based $\mathrm{NiO} / \mathrm{MgO}$ Nanocomposite for Potentiometric Determination of Doxorubicin Hydrochloride in Commercial Injections and Human Plasma. In Polymers 12(12). https://doi.org/10.3390/polym12123066.

Alharthi, S. S., Fallatah, A. M., \& Al-Saidi, H. M. (2021). Design and Characterization of Electrochemical Sensor for the Determination of Mercury(II) Ion in Real Samples Based upon a New Schiff Base Derivative as an Ionophore. In Sensors 21(9). https://doi.org/10.3390/s21093020.

Al-Mohaimeed, A. M., Mostafa, G. A. E., \& El-Tohamy, M. F. (2021). New Construction of Functionalized $\mathrm{CuO} / \mathrm{Al} 2 \mathrm{O} 3$ Nanocomposite-Based Polymeric Sensor for Potentiometric Estimation of Naltrexone Hydrochloride in Commercial Formulations. In Polymers 13(24). https://doi.org/10.3390/polym13244459.

Amr, A., Kamel, A. H., Almehizia, A. A., Sayed, A., \& Abd-Rabboh, H. (2021). Solid-Contact Potentiometric Sensors Based on Main-Tailored Bio-Mimics for Trace Detection of Harmine Hallucinogen in Urine Specimens. Molecules (Basel, Switzerland), 26(2), 324. https://doi.org/10.3390/molecules26020324.

Badakhshan, S., Ahmadzadeh, S., Mohseni-Bandpei, A., Aghasi, M., \& Basiri, A. (2019). Potentiometric sensor for iron (III) quantitative determination: experimental and computational approaches. $B M C$ Chemistry, 13(1), 131. https://doi.org/10.1186/s13065-019-0648-x.

Elbehery, N. H. A., Amr, A. E.-G. E., Kamel, A. H., Elsayed, E. A., \& Hassan, S. S. M. (2019). Novel Potentiometric 2,6-Dichlorophenolindo-phenolate (DCPIP) Membrane-Based Sensors: Assessment of Their Input in the Determination of Total Phenolics and Ascorbic Acid in Beverages. In Sensors 19(9). https:// doi.org/10.3390/s19092058.

El-Naby, E. H. (2019). Potentiometric Signal Transduction for Selective Determination of 1-(3Chlorophenyl)piperazine "Legal Ecstasy" Through Biomimetic Interaction Mechanism. In
Chemosensors

$7(3)$.

https://doi.org/10.3390/chemosensors7030046.

Golcs, Á., Horváth, V., Huszthy, P., \& Tóth, T. (2018).

Fast Potentiometric Analysis of Lead in Aqueous Medium under Competitive Conditions Using an Acridono-Crown Ether Neutral Ionophore. In Sensors 18(5). https://doi.org/10.3390/s18051407.

Hakim S, A., Sebayang, K., Situmorang, M., Tarigan, K., Sembiring, K., Mihardi, S., \& Waruwu, E. (2021). Characterization of indicator electrodes using the potentiometric biosensor method as urea sensor with XRD, SEM-EDS, UV-Vis and FTIR. Journal of Physics: Conference Series, 1816, 12088. https://doi.org/10.1088/17426596/1816/1/012088.

Hakim, S.A., Sembiring, T., Tarigan, K., Sebayang, K., Situmorang, M., \& Noer, N.M. (2019). Characterization of Membrane PVA-Enzyme Coated PVC-KTpCIPB as Urea Sensor with Potentiometric Method. Rasayan Journal of Chemistry, 12, 780-786. https://doi.org/10.31788/RJC.2019.1225143

Hakim, S.A., Tarigan, K., Situmorang, M., \& Sembiring, T. (2018). Synthesis of Urea Sensors using Potentiometric Methods with Modification of Electrode Membranes Indicators of ISE from PVAEnzymes Coating PVC-KTpClPB. Journal of Physics: Conference Series, 1120, 12024. https://doi.org/10.1088/17426596/1120/1/012024.

Hassan, S. S. M., H. Kamel, A., Amr, A. E.-G. E., AbdRabboh, H. S. M., Al-Omar, M. A., \& Elsayed, E. A. (2020). A New Validated Potentiometric Method for Sulfite Assay in Beverages Using Cobalt(II) Phthalocyanine as a Sensory Recognition Element. In Molecules 25(13). https://doi.org/10.3390/molecules25133076.

Hassan, S., Abdelbasir, S. M., Fathy, M. A., Amr, A., AlOmar, M. A., \& Kamel, A. H. (2019). Gold Plate Electrodes Functionalized by Multiwall Carbon Nanotube Film for Potentiometric Thallium(I) Detection. Nanomaterials (Basel, Switzerland), 9(8), 1160. https://doi.org/10.3390/nano9081160.

Hassan, S., H Kamel, A., Amr, A., Hashem, H. M., \& Bary, E. (2020). Imprinted Polymeric Beads-Based Screen-Printed Potentiometric Platforms Modified with Multi-Walled Carbon Nanotubes (MWCNTs) for Selective Recognition of Fluoxetine. Nanomaterials (Basel, Switzerland), 10(3), 572. https://doi.org/10.3390/nano10030572.

Huang, S., Luo, F., \& Lai, X. (2014), Novel Potentiometric Sensors of Ion Imprinted Polymers for Specific Binding of Yttrium (III), Asian Journal of Chemistry; 26(20). 6787-6790. https://doi.org/10.14233/ajchem.2014.16795 
Kamel, A. H., Amr, A. E.-G. E., Ashmawy, N. H., Galal, H. R., Almehizia, A. A., Youssef, T. A., Al-Omar, M. A., \& Sayed, A. Y. A. (2020). Validation of a Novel Potentiometric Method Based on a Polymeric PVC Membrane Sensor Integrated with Tailored Receptors for the Antileukemia Drug Cytarabine. In Polymers 12(6). https://doi.org/10.3390/polym12061343.

Kaur, H., Chhibber, M., \& Mittal, S. K. (2017). Acyclic Arylamine-Based Ionophores as Potentiometric Sensors for $\mathrm{Zn} 2+$ and $\mathrm{Ni2}+$ Ions. In C. 3(4). https://doi.org/10.3390/c3040034.

Mir, M., Lugo, R., Tahirbegi, I. B., \& Samitier, J. (2014). Miniaturizable Ion-Selective Arrays Based on Highly Stable Polymer Membranes for Biomedical Applications. In Sensors 14(7). https://doi.org/10.3390/s140711844.

Pomećko, R., Luboch, E., \& Jeszke, M. (2021). Dipodal Tetraamide Derivatives of 1,10-Diaza-18-Crown-6 and Alkylmalonic Acids-Synthesis and Use as Ionophores in Ion Selective Membrane Electrodes. Sensors (Basel, Switzerland), 21(15), 4984. https://doi.org/10.3390/s21154984.

Rahman, M. A., Kumar, P., Park, D.-S., \& Shim, Y.-B. (2008). Electrochemical Sensors Based on Organic Conjugated Polymers. Sensors, 8(1), 118-141. https://doi.org/10.3390/s8010118.

Rizk, N. M., Abbas, S. S., Hamza, S. M., \& Abd ElKarem, Y. M. (2009). Thiopental and Phenytoin as Novel Ionophores for Potentiometric Determination of Lead (II) Ions. Sensors (Basel, Switzerland), $\quad 9(3), \quad$ 1860-1875. https://doi.org/10.3390/s90301860.

Shawky, A. M., \& El-Tohamy, M. F. (2021). Highly Functionalized Modified Metal Oxides Polymeric Sensors for Potentiometric Determination of Letrozole in Commercial Oral Tablets and Biosamples. Polymers, 13(9), 1384. https://doi.org/10.3390/polym13091384.

Ulianas, A., Heng, L. Y., \& Ahmad, M. (2011). A biosensor for urea from succinimide-modified acrylic microspheres based on reflectance transduction. Sensors (Basel, Switzerland), 11(9), 8323-8338. https://doi.org/10.3390/s110908323 